\title{
Center for Electronics and Electrical Engineering
}
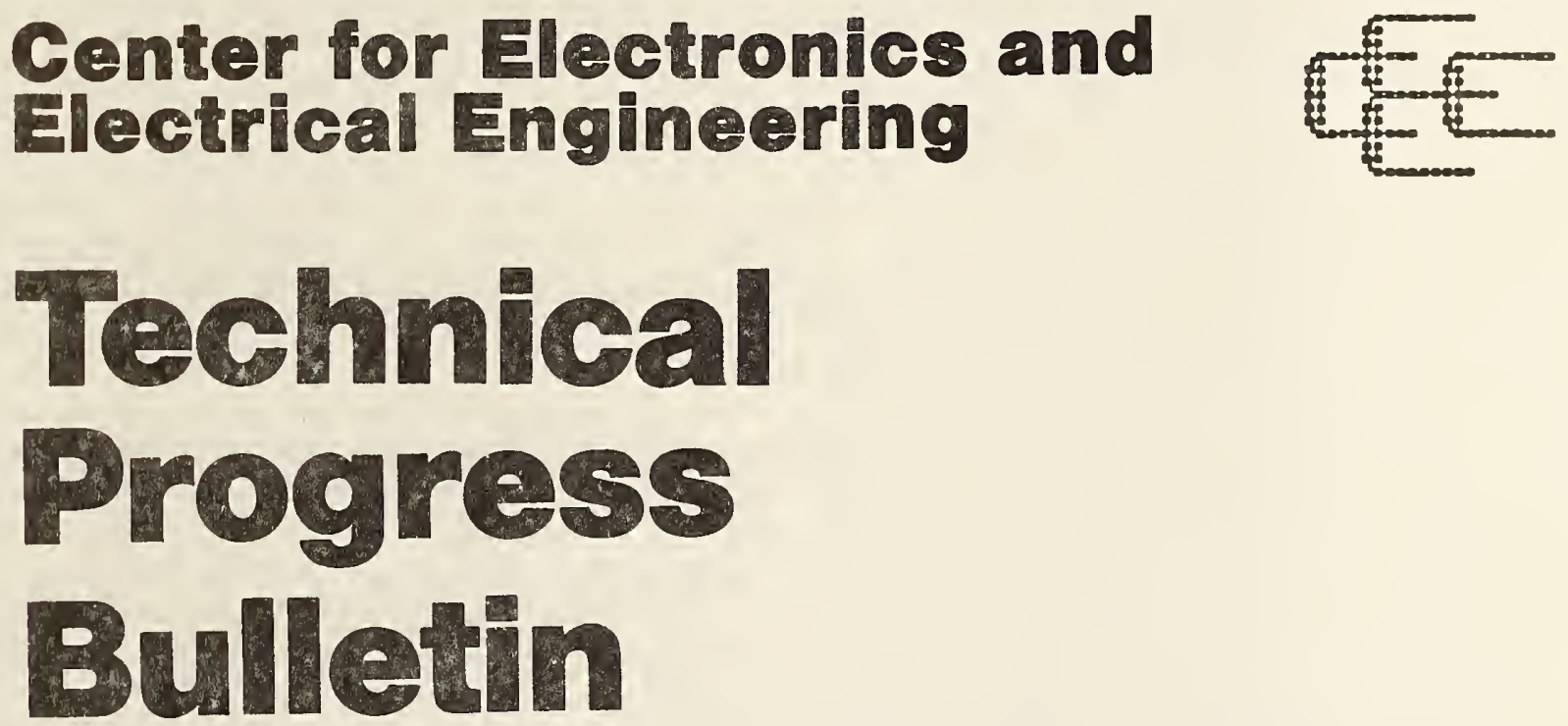

Covering Center Programs, October - December 1984 with 1985 CEEE Events Calendar

June 1985

U.S. Department of Commerce

National Bureau of Standards

National Engineering Laboratory

Gaithersburg, Maryland 20899

QC

100

.456

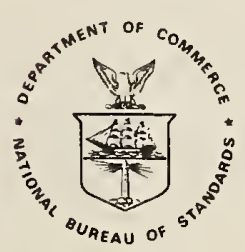

N0.85-3181

1985 
This is the ninth issue of a quarterly publication providing information on the technical work of the National Bureau of Standards Center for Electronics and Electrical Fngineering. This issue of the CEEE Technical progress Bulletin covers the fourth quarter of calendar year 1984.

Organization of Bulletin: This issue contains abstracts for all Center papers released for publication by NBS in the quarter and citations and abstracts for Center papers published in the quarter. Entries are arranged by technical topic as identified in the table of contents and alphabetically by first author under each subheading within each topic. Unpublished papers appear under the subheading "Released for Publication". Papers published in the quarter appear under the subheading "Recently Published". Following each abstract is the telephone number of the individual to contact for more information on the topic; unless otherwise noted, this person is the first author. This issue also includes a calendar of center conferences and workshops now planned for calendar year 1985, an announcement of newly released standard reference materials, and a list of sponsors of the work.

Center for Electronics and Electrical Engineering: Center programs provide national reference standards, measurement methods, supporting theory and data, and traceability to national standards.

The metrological products of these programs aid economic growth by promoting equity and efticiency in the marketplace, by removing metrological barriers to improved productivity and innovation, by increasing U. S. competitiveness in international markets through facilitation of compliance with international agreements, and by providing technical bases for the development of voluntary standards for domestic and international trade. These metrological products also aid in the development of rational regulatory policy and promote efficient functioning of technical programs of the Government.

The work of the Cencer is divided into two major programs: the Semiconductor Technology program, carried out by the semiconductor Materials and Processes and Semiconductor Devices and Circuits Divisions in Gaithersburg, MD, and the Signals and systems Metrology Program, carried out by the Electrosystems Division in Gaithersburg and the Electromagnetic Fields and Electromagnetic Technology Divisions in Boulder, CO. Key contacts in the Center are given on the back cover; readers are encouraged to contact any ot these individuals for further information. To request a subscription or for more information on the Bulletin write to CEEE Technical Progress Bulletin, National Bureau of Standards, Metrology Building, Room B-358, Gaithersburg, MD 20899 or call (301) 921-3357.

Center sponsors: The Center programs are sponsored by the National Bureau of Standards and a number of other organizations, in both the Federal and private sectors; these are identified on page 27.

Note on Publication Lists: Guides to earlier as well as recent work are the publication lists covering the work of each division. These lists are revised and reissued on an approximately annual basis and are available from the originating division [publications from the Semiconductor Technology Program are covered in a single list, available from either Semiconductor Division]. 
Insulators and Interfaces, cont'd.

rials and for the calibration of reference standards for thin film thickness and refractive index.

[(301) 921-3625]

Dimensional Metrology

Recently published

Nyyssonen, D., Optical Linewidth Measurement on Patterned Metal Iayers, Proc. SPIE - The International Society tor optical Engineering, 480, Integrated Circuit Metrology II, pp. 2-8 [paper given at Conference, Arlington, VA, May 2-3, 1984].

In a previous paper, a waveguide model was developed for the imaging of micrometer-sized lines patterned in thick layers of dielectric materials (silicon dioxide) with application to linewidth measurement on integratedcircuit wafers. This paper describes the extension of this work to metals characterized by their complex index of refraction, $n+i k$, as well as the inclusion of a sublayer such as a silicon dioxide insulating layer. This extension allows the modeling of optical imaging and linewidth measurement on metal-on-silicon (MOS) structures. It is shown that the image structure for metals at and near focus is different from that for dielectrics. Thick and thin layer (less than $200 \mathrm{~nm}$ ) imaging is compared. Experimental image profiles of metal lines at and near focus are also shown. The experimental data were obtained from a bright-field microscope using a laser source $(530 \mathrm{~nm})$ and controlled spatial coherence.

[(301) 921-3786]

Gallium Arsenide Materials

Released for Publication

Imhoft, E.A., Bell, M.I., and Forman, R.A., Hot Photoluminescence in Beryllium-Doped Gallium Arsenide.
Hot photoluminecence in GaAs:Be is reported for the first time. The emission from a sample with $\mathrm{p}=6.5 \times 10^{16} \mathrm{~cm}^{-3}$ at $10 \mathrm{~K}$ consists of a shoulder at 1.803 $\pm 0.002 \mathrm{eV}$ followed by a series of broad peaks at $1.781,1.742,1.704,1.666$, and $1.628 \mathrm{eV}($ all $\pm 0.003 \mathrm{eV})$. Analysis of the results supports a decay model involving hot electron-acceptor recombination and implies an $L-\Gamma$ splitting of $320 \pm 4$ meV in the conduction band at $0 \mathrm{~K}$. [Contact: Bell, (301) 921-3786]

Recently published

Seabaugh, A.C., Bell, M.I., Larrabee, R. D., and Oliver, J.D., High-Frequency Transient-Resistance spectroscopy of Deep Ievels in Semi-Insulated GaAs, Semi-Insulating III-V Materials: Kahneeta 1984, D.C. Look and J.S. Blakemore, Eds., pp. 437-445 (Shiva Publishing, Ltd., Cheshire, England, 1984).

A new photoinduced transient-resistance technique is used to characterize deep levels in semi-insulating GaAs. In this technique, termed photoresistance deeplevel transient spectroscopy (PR-DLTS), an optical pulse is used to generate excess carriers which are trapped by deep levels in the material. The ac resistance of the specimen is monitored, and the resistance transient which occurs after the illumination ends is signal processed in the same way as the capacitance transient in conventional DLTS. Comparison of this technique with the dc current-transient measurement, photoinduced transient spectroscopy (PITS), shows that it is sensitive to the same trapping/detrapping phenomena. PR-DLTS data for the cr-related deep level is consistent with published DLTS results. Results are reported for materials grown by the horizontal Bridgman method and by the liquid-encapsulated Czochralski technique, both with and without chromium doping. Ninetern specimens from ten different manufacturers are compared.

[ (301) 921-3625] 
Integrated Circuit Test Structures

Released for Publication

Cassard, J.M., KEYS: A Computer Procedure Which Characterizes a Chip, Wafer, or Lot Using SUXES and STRM2.

The computer procedure KEYS links SUXES, SPICE, and STAT2. Given data points for individual devices, SUXEs obtains the model parameters for SPICE which predicts the behavior of an individual device or an entire circuit. After analyzing each test chip on a wafer, STAT2 determines the correlation coefficients and generates wafer maps of selected parameters. These wafer maps are valuable to the designer, modeler, and process engineer.

The entire package accomplishes the following: (1) standardizes the technique of running SUXES and SPICE; (2) simulates and plots the characteristic curves; (3) simulates and plots the results of an optional dynamic circuit (for example, a ring oscillator); (4) does steps (2) and (3) for every test chip on each wafer; (5) summarizes the results from each chip, each wafer, and the lot; (6) rank-orders the parameters for each wafer according to their correlation coefficients with respect to chosen parameters; and (7) generates water maps of several quantities. To illustrate the capabilities of KEYS, an example using CMOS technology is given. [ (301) 921-3621]

Linholm, L.W., Yen, D., and Cresswell, M.W., Electrical Linewidth Measurement in the Near- and Sub-Micron Linewidth Region.

The measurement accuracy of the crossbridge resistor test structure and test method has been compared to well-characterized optical measurements for samples with near-micron and sub-micron design dimensions patterned in polysilicon films. Results are presented which show that the electrical measurements agree with the corresponding optical measure- ments to within the respective uncertainties of both measurements. [ (301) 921-3541]

\section{Recently Published}

Carver, G.P., and Wachnik, R.A., TERRY-2: A Test Chip for Characterization of the Performance of Buried-Channel Charge-Coupled Device (CCD) Imagers, NBSIR 84-2894 (December 1984).

Test chip TERRY-2 is intended to be used for characterization of the performance of buried-channel charge coupled device (CCD) imagers fabricated with a doublepolysilicon-gate process which includes several implants. Test structures in TERRY-2 address two areas judged to be key ones for CCD performance: device parameters and process parameters, including material properties. TERRY-2 is a modular chip designed for automatic testing; selected devices can be wire bonded for testing various environmental effects; a region containing test structures can be thinned in the same manner as a back-side-illuminated CCD would be; and large devices can be beveled for spreading resistance or physical analysis. This report describes the features of TERRY-2, the test structure designs, and the measurement procedures. The technique of charge pumping for measuring interface state density is discussed in an appendix.

[ (301) 921-3786]

Process and Device Modeling

Released for Publication

Bennett, H.S., Band structure and Density of states Changes for Doped Gallium Arsenide, to be published in the Technical Program of Topical Conference on Basic Optical Properties of Ma terials, May 7-9, 1985, Gaithersburg, Maryland.

Optical absorption measurements on doped GaAs are interpreted in terms of distorted band structures. Such data provide values for the many-body interactions which are essential in 
Process and Device Modeling, cont'd.

calculations on the operation of lasers and opto-electronic devices.

[(301) 921-3541]

Bennett, H.S., Modeling GaAs/AlGaĀs Devices: A Critical Review.

Device models for GaAs devices and GaAs/AlGaAs heterostructures are much less advanced than those for silicon devices. This paper critically reviews recent advances in the modeling of GaAs/AlGaAs devices. It is based on the examination of five selected device models which contain features common to the majority of device models for heterostructure bipolar and field effect transistors. Areas requiring improved measurement techniques on processed GaAs and improved physical concepts for GaAs/AlGaAs device models are identified.

[ (301) 921-3541]

Bennett, H.S., and Fuoss, D.E., Improved Physics for Simulating Submicron Bipolar Devices.

The conventional device physics in most numerical simulations of bipolar transistors may not predict correctly the measured electrical performance of shallow, heavily doped emitters and bases. This paper presents improved device physics for numerical simulations of solid-state devices with densities up to about $3 \times 10^{20} \mathrm{~cm}^{-3}$ and with junction depths as small as $0.1 \mu \mathrm{m}$. This improved device physics pertains to bandgap narrowing, effective intrinsic carrier concentrations, carrier mobilities, and lifetimes. When this improved device physics is incorporated into device analysis codes such as SEDAN and then used to compute the electrical performance of npn transistors, the predicted values agree very well with the measured values of the current-voltage characteristics and dc common emitter gains for junction depths between 10 and $0.16 \mu \mathrm{m}$. [(301) 921-3541]
Recently Published

Albers, J., Wilson, C.L., and Blue, J.L., The Effect of Bevel Angle and Number of Points on Spreading Resistance Data Analysis, Extended Abstracts of the Electrochemical Society, 84-2, p. 727 (October 1984).

The semiconductor equations are used to obtain the carrier profile along a beveled structure. The spreading resistance is calculated on a scale much finer than the present experimental resolution of the technique. Spreading resistance algorithms are used on data spaced at the present experimental resolution. The difference between atomic and carrier densities along the bevel and the errors inherent in finite-layer algorithms are investigated. This is meant to provide insight into limitations of spreading resistance due to these sources.

[(301) 921-3621]

Bennett, H.S., Dependence of Minority Carrier Lifetime on Doping Density in Heavily Doped Silicon, Solid-state Electronics, 27, pp. 893-904 (October 1984).

The minority carriers determine the essential electrical characteristics of bipolar devices and bipolar-like parasitic paths in field effect devices. The electrical behavior of such devices is frequently described by detailed device models. Among the several input parameters for detailed device models, the dependences of the minority carrier lifetimes as functions of doping density have great uncertainty. Recent results from scattering theory for bandgap narrowing and Fermi energy as functions of doping density are included in the Shockley-Read-Hall expressions for the minority carrier lifetimes. The prodicted lifetimes are concave from above with increasing doping for those processing conditions under which the doping and defect densities are nor correlated strongly, whereas emplrical 
Process and Device Modeling, cont'd.

expressions for the Shockley-Read-Hall lifetimes are convex with increasing doping density. Quantitative comparisons between theory and experiment are not possible because measurements of lifetime versus doping density have uncertainties associated with the separation of the Shockley-Read-Hall and Auger recombination mechanisms. A major finding of this research is that improved measurements are needed for minority carrier lifetime in heavily doped silicon as a function of doping density.

[(301) 921-3541]

Berkowitz, H.L., and Albers, J., Simplified Method for Calculating FourProbe Resistances on Nonuniform Structures, Extended Abstracts of the Electrochemical society, 84-2, p. 751 (October 1984).

A simple method for calculating the four-probe resistance as an integral involving only the kernel of the correction factor integral (and independent of the probe radius and the probe-current density) is presented. Analytic expressions are derived for uniform layers and are investigated as a function of the probe spacing. For nonuniform resistivity structures, a simple numerical procedure is presented for the evaluation of the four-probe resistance and is compared with more extensive techniques. [Contact: Albers, (301) 921-3621]

\section{Galloway, K.F., Measurements for VLSI Models, Proceedings of the second International workshop on the Physics of Semiconductor Devices, S.C. Jain and S. Radhakrishna, Eds. (Tata McGraw- Hill, New Delhi, 1984), pp. 98-105.}

The complexity of VLSI makes an experimental approach to design and fabrication unrealistic. Accurate, computerbased models for simulating processes, devices, and circuits are required to competitively develop VLSI technologies.
The effectiveness of these models is often limited by the accuracy of the physical parameters used as input for the simulations. This paper summarizes results from two recent projects on measurement technology for obtaining parameters for VISI models to illustrate the research in this area at the National Bureau of standards.

[ (301) 921-3541]

Wilson, C.L., and Blue, J.L., TwoDimensional Modeling of $\mathrm{N}$-Channel MOSFETS Including Radiation-Induced Interface and oxide Charge, IEEE Transactions on Nuclear Science, NS-31, No. 6, pp. 1448-1452 (December 1984).

A model of the radiation-induced charges produced in n-channel MOSFETs is presented. The model is applicable for the unirradiated device and accurately predicts device characteristics for doses of up to $500 \mathrm{krad}(\mathrm{Si})$. The model is verified by comparing the results obtained with the model to n-channel MOSFETs for doses of $0,10,50,100$, and $500 \mathrm{krad}(\mathrm{Si})$. Detailed comparison of the model with a 7.8- $\mu \mathrm{m}$ channel length transistor, to eliminate short-channel effects, shows excellent agreement between the model and measured currentvoltage characteristics in the subthreshold region, the triode region, and the saturation region. Analysis of the model parameters shows that the oxide charge and interface trap density are linear with dose in these devices. The mobility decrease used in the model can best be accounted for by the combined effects of scattering from oxide and interface charge in the channel.

[ (301) 921-3541]

Wilson, C.L., Roitman, P., Marchiando, J.F., and Blue, J.L., Modeling of the Process Sensitivity of Submicron Silicon MOSFErs, Extended Abstracts of the Electrochemical Society, 84-2, p. 709 (October 1984).

When short-channel MOSFET transistor models are compared to experimental 
Process and Device Modeling, cont'd.

data, the uncertainty in the process models used as inputs often requires that some of the process model parameters be adjusted to fit the data. In this work the process sensitivity of the source-drain junction is modeled. We find that sensitivity of the saturated drain current to the source-drain junction depth increases sharply at some critical value of the junction depth. This value of junction depth is reached when the junction depth is equal to the zero biased depletion region width. As the contribution of the source drain junction to the sum of the depletion width and the junction depth becomes significant, the total change in channel field caused by the source-drain junction is a maximum.

[ (301) 921-3541]

$\underline{\text { Radiation Effects }}$

Recently Published

Gaitan, M., and Russell, T.J., Measurement of Radiation-Induced Interface Traps Using MOSFETs, IEEE Transactions on Nuclear Science, NS-31, No. 6, pp. 1256-1260 (December 1984).

The effect of gamma irradiation on the density of $\mathrm{SiO}_{2} / \mathrm{Si}$ interface traps was measured using $\mathrm{n}$ - and p-channel MOSFETs. The density of traps was measured by a charge pumping measurement method and by a technique based on the slope of the transistor In $\left(I_{d}\right)-V_{g}$ characteristics in weak inversion. An increase in the density of interface traps with dose is observed with a greater increase just above compared to just below the center of the silicon bandgap.

[(301) 921-3621]

Galloway, K.F., Gaitan, M., and Russell, T.J., A Simple Model for separating Interface and Oxide Charge Effects in MOS Device Characteristics, IEEE Transactions on Nuclear Science, NS-31, No. 6, pp. 1497-1501 (December 1984).
A simple model to describe radiation effects on MOSFET electrical characteristics is presented. The key assumption is that mobility degradation in an enhancement mode MOSFET is predominantly due to charged interface traps. Model predictions are compared with measured values of interface trap density and device $I-V$ curves.

[(301) 921-3541]

\section{FAST SIGNAL ACQUISITION, PROCESSING AND TRANSMISSION}

Waveform Metrology

Released for Publication

Gans, W.L., Picosecond Pulse waveform Error Analysis at NBS, to be published in the forthcoming special issue of the Proceedings of the IEEE on Radio Measurement Methods and Standards (invited paper) [related version to be published in the proceedings of the IMTC/85 Instrumentation/Measurement Te chnology Conference, Tampa, FL, March 21-22, 1985].

The primary system used at NBS, Boulder to measure fast ( $p$ icosecond-nanosecond range), repetitive, electrical pulse parameters consists essentially of a wideband (dc-18 GHz) sampling oscilloscope interfaced to a minicomputer. This paper describes the major calibration and analysis techniques used to reduce the effects of errors inherent in this system, both deterministic and random in nature.

[ (303) 497-3538]

Lawton, R.A., Riad, S.M., and Andrews, J.R., Pulse and Time Domain Measurements, to be published in the forthcoming special issue of the proceedingys of the IEEE on Radio Measurement Methods and standards (invited paper).

A review of the state of the art and science of pulse measurements is given including recent advances in the use of real time oscilloscopes, waveform rocorders, equivalent time sampling oscli- 
Wavetorm Metrology, cont'd.

loscopes and counter timers in the measurenent of repetitive and single transient signals. Recent advances in the use of artifact waveform standards and modern signal analysis techniques to compensate for measurement distortion are highlighted. The formation and progress of an IEEE committee which is developing a performance standard for wavetorm recorders is also described. [(303) 497-3339]

Recently published

Lawton, R.A., Nahman, N.S., and Bigelow, J.M., A Solid-state Reference Waveform standard, IEEE Transactions on Instrumentation and Measurement, IM-33, No. 3, pp. 201-205 (September 1984).

A solid-state reference waveform filter has been developed which uses the Maxwell-wagner capacitor effect. This filter is realized in a stripline configuration with a lossy dielectric con-

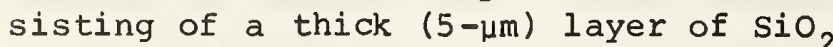
on si. The equivalent circuit of this filter is equivalent to that for previously developed filters which used a lossy liquid dielectric. A preliminary design has been completed and a filter fabricated for which the design characteristıc impedance, $38 \Omega$, and transition duration ( $r i s e$ time), 300 ps, agree with measured values to within 2 and 17 percent, respectively. The temperature dependence of the filter transition duration has been estimated from the temperature dependence of the filter conductance to be about 1 percent $/{ }^{\circ} \mathrm{C}$. [(303) 497-3339]

\section{Cryoelectronic Metrology}

Released for Publication

Kautz, R.I., Chaos and Thermal Noise in the rf-Biased Josephson Junction.

The etfect of thermal noise on chaotic behavior in the rf-biased Josephson junction is studied through digital simulations.

Metastable chaotic states are identified in the limit of zero temperature. Such states take the form of long-lived transients which suddenly give way to stable periodic solutions. It is shown that for an ensemble of systems in the metastable chaotic state, the number of systems continuing to behave chaotically decays exponentially in time. This result suggests that a deterministic system can display behavior analogous to radioactive decay.

At non-zero temperatures, small amounts of thermal noise can induce hopping between two states which correspond to a stable periodic solution and a metastable chaotic solution at zero temperature. The noise associated with thermally induced hopping can exceed that of chaos and could be confused with chaos in experimental investigations. At somewhat higher temperatures, the periodic solution is destabilized to the point where the system spends virtually all its time in the metastable chaotic state, creating thermally induced chaotic behavior. The similarities between chaotic behavior at zero temperature and thermally induced chaos are sufficiently strong that it may be difficult to distinguish the two cases experimentally. [(303) 497-3391]

MCGrath, W.R., Ralsanen, A.V. , Richards, P.I., Harris, R.E., and Lloyd, F.L., Accurate Noise Measurements of Superconducting Quasiparticle Array Mixers, to be published in the proceedings of the 1984 Applied Superconductivity Conference, San Diego, CA, September 9$13,1984$.

We have constructed a $30-40 \mathrm{GHz}$ test apparatus which allows us to measure the noise temperatures of SIS mixers with an accuracy of better than $\pm 1 \mathrm{~K}$. This is a factor of six improvement over earlier measurements. The most accurate measurement made thus far of a mixer which uses a single $\mathrm{Pb}-\mathrm{alloy}$ junction yielded $\mathrm{T}_{\mathrm{M}}=9.2 \pm 0.9 \mathrm{~K} ;$ and mixer gain: 
Cryoelectronic Metrology, cont'd.

$C_{M}=0.240 \neq 0.005$. In addition, sIS mixers employing arrays of $\mathrm{N}=1,5,10$, 25, and 50 tunnel junctions in series have been tested. The input power required to saturate the array mixers was found to increase as $\mathrm{N}^{2}$ and the gain and noise temperature of the array mixers were independent of $\mathrm{N}$.

[Contact: Harris, (303) 497-3210]

Recently Published

Hamilton, C.A., Lloyd, F.L., and Kautz, R.L., High Speed superconducting A/D Converter, Proc. 1984 Government Microcircuit Applications Conference, Las Vegas, NV, Nov. 6-8, 1984, pp. 140143.

Superconducting electronics has demonstrated impressive performance capabilities for small digital systems and analog signal processing applications. One of the areas where superconductivity offers a unique advantage is in ultrahigh speed $A / D$ conversion. This paper will describe the operation and current status of a 6-bit, 4 gigasample/s A/D converter which has been developed at NBS.

[ (303) 497-3740]

McDonald, D.G., Amplification by the Phase-Locking Mechanism in a FourJunction SQUID, Applied Physics Letters, 45, No. 11, pp. 1243-1245 (1 December 1984).

It is shown that the phase-locking property of an array of Josephson junctions can be used as a basis for amplification. The particular device simulated is a superconducting quantum interference device (SQUID) with four junctions in the loop, rather than the usual one or two. Novel consequences of this design are that it allows direct rather than inductive coupling to the SQUID and, because of its potentially compact form, it probably can have a bandwidth well into the gigahertz range, in agreement with the simulatjons.

[(303) 497-5113]
Niemeyer, J., Hinken, J.H., and Kautz, R.L., Microwave-Induced ConstantVoltage steps at one Volt from a Series Array of Josephson Junctions, Applied Physics Letters, 45, No. 4, pp. 478-480 (15 August 1984).

It is demonstrated that a series array of 1474 Josephson junctions can produce quantized voltages up to $1.2 \mathrm{~V}$ when driven by microwaves at $90 \mathrm{GHz}$ in the absence of a dc bias. This result brings closer the possibility of a practical Josephson voltage standard at the 1-V level.

[Contact: Kautz, (303) 497-3391]

Zimmerman, J. E., Recent Developments in Self-Contained cryocoolers for SQUIDs and other Low-Power cryoelectronic Devices, Proc. Tenth International Cryogenic Engineering conference, Helsinki, Finland, July 31-August 3, 1984, pp. 13-19.

The particular requirements of refrigeration for very low power cryoelectronic devices have been addressed only during the last few years. A number of laboratory prototypes are now near realization, and commercial systems may be available soon. These include stirling and Gifford-McMahon machines and a fourstage Joule-Thomson machine, or a combination of one of the former with a final Joule-Thomson stage to achieve $4 \mathrm{~K}$, and small liquid-helium cryostats with integral intermittent re-liquefying capability. The most difficult technical problem outstanding is to design reliable, non-contaminating, miniature compressors for these machines.

[(303) 497-3901]

Antenna Metrology

Released for Publication

Jesch, R.L., Measured Vehicular Antenna Performance.

Power gain radiation patterns of mobllo antennas mounted in six diffrrent locntions on a test vehicle were meatured 
Antenna Metrology, cont'd.

with and without typical lights and sirens mounted on the roof. The measurements were performed at frequencies representing the frequency bands of 25 to 50,150 to 174,400 to 512 and 806 to $866 \mathrm{MHz}$. In addition, special antennas consisting of three disguised antennas operating at discrete frequencies of $40.27,162.425$, and $416.975 \mathrm{MHz}$ and one slot antenna operating at $413 \mathrm{MHz}$ were also measured. Plots of power gain radiation patterns are given for the mobile antenna mounted in six different locations on the test vehicle and for the special antennas. Results showing the effects of poor grounding characteristics are also included. Recommended locations for mounting the mobile antennas are given.

[(303) 497-3496]

Newell, A.C., Francis, M.H., Kremer, D.P., and Grimm, K.R., Results of Planar Near Field Testing with Ultralow Sidelobe Antennas, to be published in the Proceedings of the North American Radio science Meeting and International IEEE/AP-S Symposium, Vancouver, Canada, June $17-21,1985$.

An investigation to demonstrate Planar Near Field (PNF) measurement accuracy for ultralow sidelobe antennas is nearing completion at the National Bureau of standards, Boulder, CO. The existing NBS scanner has been modified to accommodate antennas up to $10 \mathrm{~m}$ long and $4 \mathrm{~m}$ high. Two antennas will be measured as a part of this research effort. They are the AWACS (U.S. Airborne Warning and Control System) and the ULSA (Ultra Low Sidelobe Antenna), traveling wave antennas which are respectively $8 \mathrm{~m} \mathrm{X} 1.5 \mathrm{~m}$ and $6 \mathrm{~m} \times 1 \mathrm{~m}$. Results of tests to introduce controlled NF measurement error confirm predicted far field (FF) sidelobe accuracies at the $-60 \mathrm{~dB}$ level. Additional results show the utility of a new 2element probe to extend sidelobe measurement accuracy by steering a probe pattern null in the direction of the test antenna's mainbeam.

\section{$[(303) \quad 497-3743]$}

Wittmann, R.C., and Yaghjian, A.D., The Receiving Antenna as a Linear Differential operator: Application to Spherical Near-Field Scanning.

The general receiving antenna is represented as a linear differential operator converting the incident field and its derivatives at a single point in space $\left(0^{\prime}\right)$ to the output voltage of the receiving antenna. The coefficients of the derivatives of the operator are determined explicitly in terms of the multipole coefficients of the antenna's receiving spectrum (far field) phasereferenced to the point $0^{\prime}$. When the linear operator representation is applied to the special probes used in spherical near-field measurements, a probe-corrected spherical transmission formula is revealed that retains the form and applicability of the nonprobecorrected equations. The new spherical transmission formula is shown to be consistent with previous transmission formulas involving rotational and translational addition theorems.

[ (303) 497-3326]

\section{Recently Published}

Kanda, M., Transients in a Resistively Loaded Loop Antenna, Proceedings of the 1984 International Symposium on Electromagnetic Compatibility, Tokyo, pp. 286-290 (October 16-18, 1984).

Transient characteristics of a loop antenna loaded uniformly with a resistive material are analyzed. The current distribution of the antenna is obtained by use of a Fourier series expansion technique. It is found that distortion of the transient waveforms due to resonance of a loop antenna can be reduced significantly and the received transient waveforms can be tailored by resistive loading.

[ (303) 497-5320]

Newell, A.C., Francis, M.H., and Kremer, D.P., The Determination of Near-Field 
Antenna Metrology, cont'd.

Correction Parameters for circularly Polarized Probes, Proc. Annual conference of the Antenna Measurement Techniques Association, Atlanta, GA, pp. 3A3-1 - 3A3-29 (October 2-4, 1984).

In order to accurately determine the far-field of an antenna from near-field measurements the receiving pattern of the probe must be known so that probe correction can be performed. When the antenna to be tested is circularly polarized, the measurements are more accurate and efficient if circularly polarized probes are used. Further efficiency is obtained if one probe is dual polarized to allow for simultaneous measurements of both components. A procedure used by the National Bureau of Standards for determining the plane-wave receiving parameters of a dual-mode, circularly polarized probe is described herein. First, the on-axis gain of the probe is determined using the three antenna extrapolation technique. Second, the on-axis axial ratios and portto-port comparison ratios are determined for both the probe and source antenna using a rotating linear horn. Far-field pattern measurements of both amplitude and phase are then made for both the main and cross components. In the computer processing of the data, the onaxis results are used to correct for the non-ideal source antenna polarization, scale the receiving coefficients, and correct for some measurement errors. The plane wave receiving parameters are determined at equally spaced intervals in $\mathrm{k}$-space by interpolation of the corrected pattern data.

[ (303) 497-3743]

Wittmann, R.C., Probe Correction in Spherical Near-Field Scanning, viewed as an Ideal Probe Measuring an Effective Field, 1984 International symposium Digest, Antennas and Propagation, Vol. II, pp. 674-677 [paper given at IEEE Antennas and Propagation society Meeting, Boston, MA, June 25-29, 1984].
In order to reduce measurement and computation complexity, most probecorrected, spherical near-field scanning facilities use a special "symmetric" probe, the output of which exhibits a $\sin x-\cos x$ dependence as the probe is rotated about $i$ ts axis by an angle $\chi$. We show here that such a probe is mathematically equivalent to ideal dipole probes measuring an effective field. computational efficiency and structural simplicity result, since much of the effort concerns the calculation of the effective field, and this may be accomplished with a no-probe correction algo rithm.

[ (303) 497-3326]

\section{Noise Metrology}

\section{Released for Publication}

Daywitt, W.C., Broadband Noise Source Applications, to be published in the Proceedings of the IMTC/85 Instrumentation/Measurement Technology Conference, Tampa, FL, March 21-22, 1985.

Accurate noise characterization of amplifiers and communication systems requires the use of thermal noise standards. This note is a brief review of the use of such standards as a basis for the measurement of effective input noise temperature and the G/T of a satellite earth terminal receiving system.

[(303) 497-3720]

Perera, S., Noise Temperature Measurements at the National Bureau of Standards, to be published in the proceedings of the IMTC/85 Instrumentation/Measurement Technology Conference, Tampa, FL, March 21-22, 1985.

Thermal noise presents the ultimate limitation in the reception and detection of low level electromagnetic slgnals. This paper briefly reviews the physics of thermal noise, devices that generate noise, and measurement methods to characterize noise sources.

[ (303) 497-3546] 
Noise Metrology, cont'd.

Wait, D.F., The Impact of Automation on NBS Noise Temperature Measurements, to be published in the forthcoming special issue of the proceedings of the IEEE on Radio Measurement Methods and Standards (invited paper).

The accuracy of calibrating a thermal noise source using the National Bureau of Standard's automated radiometer and cryogenic, primary noise standards is typically $\pm 2 \%$, compared with $\pm 3 \%$ for corresponding services that used manual radiometers and hot primary standards. Using the automated radiometer, a noise source can typically be calibrated at three frequencies in the time a manual radiometer requires to calibrate one. The automated radiometer contains a 6port reflectometer and noise sources with reflection coefficients as great as 0.3 can be tolerated without significantly affecting the calibration accuracy. This makes it practical to use a single broad-band, coaxial noise standard from $0.03 \mathrm{GHz}$ to $14 \mathrm{GHz}$. The 6port reflectometer also makes it possible to calibrate sources with connectors different from the primary standard's without almost no additional accuracy degradation.

[(303) 497-3610]

Recently Published

Daywitt, W.C., A Preliminary Investigation Into Using the Sun as a source for G/T Measurements, NBSIR 84-3015 (August 1984).

This report describes a preliminary investigation into determining the solar flux density, the atmospheric correction factor, and the star shape correction factor for use in G/T measurements above $5 \mathrm{GHz}$. An estimate of errors is also included. Preliminary results show: an i.mproved algorithm for determining diffusive and refractive attenuation; a viable technique for estimating the solar filux density from daily AFGL flux density measurements and a centimeter/millimeter wave spectrum function; and the possibility of reducing star shape correction factor errors by use of an effective solar rf diameter. [ (303) 497-3720]

Microwave and Millimeter-Wave Metrology

\section{Released for Publication}

Hoer, C.A., NBS Calibration services and systems, to be published in the forthcoming special issue of the proceedings of the IEEE on Radio Measurement Methods and standards (invited paper).

This paper gives a brief summary of the calibration services available at the Boulder Laboratories of the National Bureau of Standards for attenuation, phase shift, impedance, power, and voltage at rf and microwave frequencies. [ (303) 497-3705]

Kamper, R.A., Uncertainty Charts for RP and Microwave Measurements, to be published in the forthcoming special issue of the Proceedings of the IEEE on Radio Measurement Methods and Standards (invited paper).

The scope of the calibration services for electrical quantities in the range of frequency from 0 to $100 \mathrm{GHz}$ that are available from the National Bureau of standards is discussed briefly in a historical context. Some plans for improved services that will be available in the near future are noted. Charts showing the variation of uncertainty with magnitude over the full range of the respective calibration services are presented.

[(303) 497-3535]

Reeve, G.R., and Miller, C.K.S., Current NBS Metrology Capabilities and Iimitations at the Millimeter Wave Frequencies, to be published in the Proceedings of the Measurement Science Conference, Santa Clara, CA, January 17-19, 1985 .

The National Bureau of Standards (NBS) establishes national artifact standards and provides a metrology base for U.S. industry and technology. In the milli- 
Microwave and Millimeter-Wave, cont'd.

meter wave frequency spectrum, NBS has not established all the needs of industry or government for this technology. It is the intent of this paper to describe the technical demands of responding to the challenges of millimeter-wave technology. A description of the current capabilities that exist at NBS will be given for those parameters and frequencies where measurement services exist. Where novel standards have been aeveloped, such as the $94 \mathrm{GHz}$ thermal noise standard, the physical basis for the standard will be described to indicate the changes from lower frequency designs and the challenges that had to be overcome. Limitations in services and in concepts of standards for providing those services will be described to indicate the degree of research that must be undertaken to satisfy future industrial needs in this evolving technology

[(303) 497-3131]

Sladek, N.J., and Jesch, R.L., standardization of Coaxial connectors in the IEC, to be published in the forthcoming special issue of the proceedings of the IEEE on Radio Measurement Methods and Standards (invited paper).

This article reviews the requirements and standardization of coaxial connectors in the United states. It details the standardization of coaxial connectors within the International Electrotechnical Commission (IEC) subcommittee SC46D "Connectors for RF Cables." A iist of published IEC connector standards and a list of IEC connectors under consideration are included.

[Contact: Jesch, (303) 497-3496]

Laser Metrology

Released for Publication

Sanders, A.A., and Case, W.E., Laser Power and Energy Measurements and the NBS Laser Measurement. Assurance Program (MAP), to be published in the Pro- ceedings of the IMTC/85 Instrumentation/Measurement Technical Conference, Tampa, FL, March 21-22, 1985.

This paper describes the national standards for laser power and energy measurements maintained by the National Bureau of standards and how the measurement services based on these standards are disseminated. Particular emphasis is devoted to the procedures and instrumentation used in these measurements. The Laser Measurement Assurance Program (MAP) is discussed in detail. The paper will also present a detailed procedure for the user to choose proper instrumentation and procedures to implement a measurements program in the laboratory. [ (303) 497-5341]

\section{Recently published}

Simpson, P.A., A Computer-Controlled System for Calibrating Detectors of TEA Laser Pulses, 22nd Automatic RF Techniques Group Fall 1983 Digest, Albuquerque, New Mexico, November 3-4, 1983, pp. 25-36 ( May 1984).

A computer-controlled system for calibrating detectors of TEA laser pulse energy and waveforms is described. The operator merely inputs certain pertinent information about the measurements to be made and the system automatically performs the measurements and outputs the results.

[(303) 497-3789]

Simpson, P.A., Johnson, E.G., Jr., and Etzel, S.M., A Calorimeter for Measuring High-Energy Optical pulses, NBSIR 84-3008 (October 1984).

Two similar calorimeters for measurincs laser pulses in the range $1 \mathrm{~kJ}$ to $15 \mathrm{~kJ}$ are described. The calorimeters, whlch are electrically calibrated, can br operated anywhere from the ultraviolot to the infrared by selecting the propror materials for the volume absorber ind deflecting mirror. Operation of wah calorimeter is controlied by a dosicutel desk-top computer. Thr thenr.etitul 
Laser Metrology, cont'd.

basis for the calorimeters is given as are the constructional and operational details. The computer programs that are used are included in the appendices. [(303) 497-3789]

\section{Optical Fiber Metrology}

\section{Released for Publication}

Yang, S., and Gallawa, R.L., Some Issues in Optical Fiber Bandwidth Measurement, to be published in the Proceedings of the IMTC/85 Instrumentation/Measurement Technology Conference, Tampa, FL, March 21-22, 1985.

This is a one-page summary of a talk to be given at IMTC. The talk will discuss the measurement of optical fiber bandwidth, using methods in common use in the tiber community. Difficulties and variabilities will be discussed.

[ (303) 497-3988]

Recently Published

Day, G.W., and Franzen, D.L., Technical Digest - Symposium on Optical Fiber Measurements, 1984, NBS Special Publication 683 (October 1984).

This volume contains summaries of 31 papers presented at the symposium on Optical Fiber Measurements held October 2-3, 1984, at the National Bureau of Standards, Boulder, Colorado. Subjects include measurements on singlemode tiber, multimode fiber, fiber designed for sensing applications, instrumentation, field measurements, and standards. [ (303) 497-5204]

Engelsrath, A., Larson, D.R., Phelan, R.J., and Franzen, D.L., Attenuation of Multimode Fused Silicon optical Fibers Cooled to Liquid Helium Temperature, Proc. SPIE - The International Society for Optical Engineering, 500, Fiber Optics: Short-Haul and Long-Haul Measurements and Applications II, pp.
124-130 [paper given at conference, San Diego, California, August 19-24, 1984].

The feasibility of bringing an optical signal through an optical fiber to a detection and processing system at liquid helium temperature was examined. The attenuation of three commercially available multimode optical fibers, from two different manufacturers with different buffer coatings, was measured under different cooling conditions. It was found that the attenuation depends on the cooling condition and has hysteresis effects. Independent of the $\lambda$ tested $(0.4-1.65 \mu \mathrm{m})$ the attenuation stayed below $0.1 \mathrm{~dB} / \mathrm{m}$ under controlled slow cooling and under $0.5 \mathrm{~dB} / \mathrm{m}$ with very fast cooling. Therefore, optical fibers can be used to bring optical signals into a liquid-helium-cooled dewar for detection and processing.

[Contact: Larson (303) 497-3440]

Maisonneuve, J.M., and Gallawa, R.L., The Use of Power Transfer Matrices in Predicting System Loss: Theory and Experiment, Proc. SPIE - The International Society for Optical Engineering, 500, Fiber Optics: Short-Haul and Long-Haul Measurements and Applications II, pp. 88-93 [paper given at conference, San Diego, California, August 1924, 1984].

The phase space diagram for parabolic and step index fibers leads to a graphic representation of the bound, leaky, and refracted rays of ray theory. This concept is used to predict the attenuation of typical components of local area networds. The technique uses power transfer matrices to track the evolution of power distribution in ray packets. In particular, we predict and then measure the power transfer of two ray packets for a step index fiber. The comparison is encouraging.

[Contact: Gallawa, (303) 497-3761]

Other Fast Signal Topics

Released for Publication 
Other Fast Signal Topics, cont'd.

Major, J.R., Li.vingston, E.M., and Adair, R.T., Automatic Frequency Response of Frequency Modulated Generators Using the Bessel Null Method, to be published in the Proceedings of the 24 th ARFTG Conference, Baltimore, MD, December 4-6, 1984.

This paper describes a Bessel null technique to measure the frequency response of a frequency-modulated rf carrier and a program to automate frequency response measurements of signal generators with output trequencies from 0.450 to 2000 $\mathrm{MHz}$. The measurements obtained using this technique are more accurate than those obtained by a highly trained technician using a manual system.

Automated measurement of this process is desirable since the manual method is subject to the following problems: (1) excessive time, (2) error in finding the null, and (3) lack of assurance that the null is the first Bessel null. This can be performed using a system controller, a spectrum analyzer, a function generator, and a voltmeter (all of which are compatible and controllable remotely (or by buss))

A major obstacle to automated measurement is the nonlinear relationship of modulating signal amplitude relative to the center frequency amplitude of the carrier. This problem was solved by obtaining an approximate formula for this nonlinear curve.

Assurance that the null found is the first Bessel null is provided in the analysis of a filtered response of the frequency versus amplitude of the test signal generator output which is displayed on the spectrum analyzer.

[ (303) 497-3149]

Young, M., and Johnson, E.G., Redefining the Scratch standards, to be published as NBS Technical Note 1080 [a related paper, Tunable Scratch Standards, authors Young, M, Johnson, E.G.,
E.G., and Goldgraben, R., was given at the SPIE 1985 Los Angeles Technical Symposium on Optical \& Electro-Optical Engineering, Conference on Measurement and Effects of surface Defects and Quality of Polish, and is to be published in the proceedings of that Conference].

The scratch standard (MIL-0-13830A) is a cosmetic standard that is effected by a visual comparison with a set of submasters that are.in turn evaluated by comparison with a set of master standards. Both manufacture and certification of the submasters are somewhat unreliable. In this paper, we show that the submasters can be classified according to the relative power scattered at a relatively small angle. We have designed etched gratings with which to replace the submasters; these gratings have the appearance of scratches but diffract a broad peak between 5 and 10 degrees off the axis of the incident beam. We have classified some prototypes both by comparison with the master standards and by a photoelectric measurement; agreement between the two methods is good. We suggest that such gratings be used as the submasters and possibly that they be classified by a photoelectric rather than visual measurement.

We have developed apparatus for measuring the scattered light from the artifact as a function of angle, using a silicon photodiode as the detector; this apparatus and its design considerations are briefly described. We applied a number of tests to evaluate the performance of this optical system, including determination of uniformity of illumination, impulse response, and detector linearity.

We also provide a discussion of basic diffraction theory, which leads to the instrumental conclusion that the width of the illuminating beam should br no greater than several hundred timen the width of the scratch.

[ (303) 497-3223] 
Other Fast Signal Topics, cont'd.

Recently Published

Be lsher, D.R., McLaughlin, R.H., Repjar, A.G., and Bussey, H.E., Microwave Detection of Lost Wells and Unknown Water-Filled Voids in Coal Mines, NBSIR 84-3017 (September 1984).

Work on contract $\mathrm{H} 0272007$ is summarized for the period of January 1979 through March 1984. The development of improved antennas usable with both a pulse system or an FM-CW system is described. The development of a field prototype pulse sampling system is described. Initial theoretical work on the problem of dielectric loading of antennas as well as a study of potential system range is included.

[Contact: Repjar, (303) 497-5703]

Hill, D.A., Radio Propagation in a Coal Seam and the Inverse Problem, NBS Journal of Research, 89, No. 5, pp. 385-394 (September-October 1984) [related paper to be published at the Conference Proceedings of the International Symposium on Antennas and EM Theory, Beijing, China, August 24-26, 1985].

The longwall method of coal mining in underground coal seams is very efficient in uniform seams, but coal seam anomalies can make the method unprofitable and unsafe. This paper describes the theoretical basis for detection of coal seam anomalies using medium frequency (MF) radio transmission over paths on the order of 200 meters in length. The key to the method is the sensitivity of the attenuation rate of the coal seam mode of propagation to changes in the coal seam parameters, such as height or electrical conductivity. From a large number of transmission paths, the principles of tomography can be used to reconstruct an image of the seam.

[ (303) 497-3472]

Lentner, K.J., Flach, D.R., and Bell,
B.A., An Automatic AC/DC Thermal Voltage Converter and AC Voltage Calibration system, NBSIR 84-2973 (November 1984).

An automatic ac/dc difference calibration system is described which uses direct measurement of thermoelement emfs. In addition to ac/dc difference testing, the system can be used to measure some important characteristics of thermoelements, as well as to calibrate ac voltage calibrators and precision voltmeters. The system operates over a frequency range from $20 \mathrm{~Hz}$ to $100 \mathrm{kHz}$, covering the voltage range from $0.5 \mathrm{~V}$ to $1 \mathrm{kV}$. For all voltages the total measurement uncertainties expected (including the uncertainty of the specific reference thermal converters used) were 50 parts per million ( $\mathrm{ppm}$ ) at frequencies from $20 \mathrm{~Hz}$ to $20 \mathrm{kHz}$, inclusive, and $100 \mathrm{ppm}$ at higher frequencies up to $100 \mathrm{kHz}$. The results of initial intercomparisons between the new system and the manual NBS calibration system, using single-range, coaxial-type, thermal voltage converters as transfer standards, are reported. The results show that the agreement between the two systems is better than the uncertainties originally expected, since the intercomparison of ac/dc differences differed by no more than $15 \mathrm{ppm}$.

[(301) 921-2727]

Sanders, A.A., some Trends in Optical Electronic Metrology, Proceedings of the 1984 Measurement Science Conference, R.M.S. Queen Mary, Long Beach, CA, January 19-20, 1984, pp. 27-33.

The use of optical related devices in high technology is expanding at a dramatic rate. Applications include the expanding use of optical fibers in telecommunications and sensors, lasers in industrial processing and medicine, optical storage devices, directed energy weapons for defensive purposes, nondestructive testing, -- the list goes on and on. The optical Electronics Metrology Group of the National Bureau of 
Other Fast Signal Topics, cont'd.

Standards has the responsibility for developing the standards, measurement data, and methodology infrastructure for supporting much of this expanding technology. This paper will review some of the ongoing research conducted by this Group and some of the perceived important technological applications in this area for the next few years. It will discuss Group plans for developing the measurement infrastructure to support these innovations. The intent is to generate a dialogue to improve the Group's planning process and help sort out the most pressing priorities for optical measurements.

[ (303) 497-5341]

Young, M., Can You Describe Optical Surface quality with One or Two Numbers?, Proc. SPIE - The International Society for Optical Engineering, 406, Optical specifications: Components and systems, pp. 12-22 [paper given at conference, April 5-7, 1983, Arlington, VA].

This talk discusses two optical surface quality standards, total integrated scatter (TIS) and the scratch and dig standard (MIL-0-13830A). I begin by using Fourier optics to show that the well known expression, $I_{t} / I(O)=4$ $\mathrm{k}^{2} \mathrm{\sigma}^{2}$, which relates scattered power to rms roughness $\sigma$, is truly valid only for certain classes of surfaces. Vector scattering theory applied to a more general case shows that in fact optics can measure only a bandwidth limited roughness that can be related to scattered power only if the surface statistics are known. For this reason, the standard should perhaps be regarded as a scattered light standard and not as a surface roughness standard. I conclude by describing our use of a novel optical system to develop an objective measurement technique to aid in the manufacture of the artifacts used to implement the scratch standard.

[ (303) 497-3223]
ETHECTRICAL SYSTTEMS

Power Systems Metrology

Released for publication

Van Brunt, R.J., Production Rates for Oxyfluorides $\mathrm{SOF}_{2}, \mathrm{SO}_{2} \mathrm{~F}_{2}$, and $\mathrm{SOF}_{4}$ in $\mathrm{SF}_{6}$ Corona Discharges.

The most abundant, long-lived stable gaseous species generated by corona discharges in $\mathrm{SF}_{6}$ gas containing trace levels of $\mathrm{O}_{2}$ and $\mathrm{H}_{2} \mathrm{O}$ are the oxyfluorides $\mathrm{SOF}_{2}, \mathrm{SO}_{2} \mathrm{~F}_{2}$ ' and $\mathrm{SOF}_{4}$. Absolute energy and charge rates-of-production of these and the minor products $\mathrm{SO}_{2}$, ICS, and $\mathrm{CO}_{2}$ have been measured at different total gas pressures from $100 \mathrm{kPa}$ to 300 $\mathrm{kPa}$ and for discharges of different current, power, and polarity. The behaviors of the observed production rates as a function of discharge conditions and the influence of $\mathrm{H}_{2} \mathrm{O}$ and $\mathrm{O}_{2}$ on oxyfluoride formation are discussed in terms of a proposed model for $\mathrm{SF}_{6}$ decomposition that is consistent with previous observations of electrical, thermal, and laser-induced decomposition of $\mathrm{SF}_{6}$ and $\mathrm{SF}_{6} / \mathrm{O}_{2}$ mixtures.

[ (301) 921-3121]

Recently published

Hillhouse, D.L., Outline of CCVT Calibration procedure, EPRI-NBS prototype system--Supplement to BPRI Report EL-690 (Field Calibration system for CCVTs, April 1978), NBSIR 84-2987 (August 1984).

This report contains, in outline form, the step-by-step procedure for use of the EPRI-NBS Prototype Field Calibration System for coupling Capacitor voltage Transformers (CCVTs) in the calibration of CCVTs in the substation. It was prepared for the use of EPRI (Elrctric Power Research Institute) personnel it waltz Mill, PA, where the system now resides. It is a supplement to the EPRI final report (EL-690, April 1978) on the project in which the system was developed. 
Power systems Metrology, cont'd.

$[(301) 921-3121]$

Pulse Power Metrology

Released for Publication

Hebner, R.E., Measurement Applications, Lecture Notes, Fiber optic Tutorial, to be published in the Proceedings of the IEEE Power Engineering Society, July 14-19, 1985, Vancouver, B. C.

This paper introduces the physics of photonic systems used to measure voltage and currents and some of the engineering aspects of the systems which must be considered in their application. Sensors based on the Faraday effect, the Pockels effect, and the Kerr effect as well as those based on mechanical effects are presented. The requirements imposed on the optical fibers by the measurement application are discussed. selected systems are described to highlight various aspects of the measurement approach.

[ (301) 921-3121]

Superconductors

Released for Publication

Fickett, F.R., Investigation of a practical superconductor with a Copper Matrix.

In this report we summarize the work performed on four International Copper Research Association projects covering a span of about six years. The main goal of the work was to investigate the insitu superconjuctors, those produced by the relatively rapid cooling of a melt containing essentially non-miscible components. The component with the higher melting point precipitates out as small particles during the cooling. Subsequent drawing of the resulting boule results in fine filaments of this material (the superconductor) in the lower-melting matrix (usually oxygen- free copper or a copper-tin alloy).

[ (303) 497-3785]

Goldfarb, R.B., and Clark, A.F., Hysteretic Losses in NbTi superconductors.

When subjected to transient magnetic fields, superconductors exhibit losses. At low frequencies, most of the dissipation is hysteretic. Hysteresis loops were measured in an axial field for eight multifilamentary NbTi superconducting wires with different filament sizes and different ratios of copper-to-superconductor. The full-penetration field $\mathrm{H}_{\mathrm{p}}$, a function of critical current density $J_{C}$ and filament radius, was estimated from the hysteresis loops. There was good agreement between measured hysteresis and that predicted from the peak applied field and $\mathrm{H}_{\mathrm{p}}$. The estimate of $\mathrm{H}_{\mathrm{p}}$ provides a method to assess $\mathrm{J}_{\mathrm{C}}$.

[(303) 497-3650]

Hong, M., Maher, D.M., Ellington, M.B., Hellman, F., Geballe, T.H., Ekin, J.W., and Holthuis, J.T., Further Investigations of the Solid-Liquid Reaction and High-Field Critical current Density in Iiquid-Infiltrated $\mathrm{Nb}-\mathrm{Sn}$ Conductors, to be published in the proceedings of the 1984 Applied Superconductivity Conference, San Diego, CA, September 9$13,1984$.

Superior superconducting properties, such as high $J_{C} ' s$ and $T_{C} ' s$, have been obtained from reacted liquid-infiltrated $\mathrm{Nb}-\mathrm{Sn}$ composite wires. These excellent properties are attributed to the chemistry and structure of the material which is prepared by a unique solid $(\mathrm{Nb})$-liquid $(\mathrm{Sn})$ reaction. From heat capacity measurements, sharp bulk superconducting transitions of the A15 phase occur at 17.2-18 $\mathrm{K}$ and the weight fraction of $\mathrm{A} 15$ in the composite wire is 23\%. Analytical electron microscopy techniques have shown that: the microstructure of these conductors consists of alternating large-grain and smallgrain filaments; these two types of 


\section{Superconductors, cont'd.}

filaments correspond to $\mathrm{BCC} \mathrm{Nb}(\mathrm{Sn})$ and cubic A1 5 Nb75 $7 x^{S n} 25 x$ phases, respectively; the A15 filaments ( $\leqslant 0.5$ $\mu \mathrm{m})$ are chemically homogeneous in terms of measured $\mathrm{x}$-ray intensity ratios to within $\pm 7 \%$ which implies that $x \sim 1.5$; and the A1 5 grains are essentially free of extended lattice disorder down to a resolution of $\sim 0.34 \mathrm{~nm}$.

Recent work in which $\mathrm{Nb}$ is alloyed with Ta has shown that these superconducting properties can be improved upon; e.g., high overall $\mathrm{J}_{\mathrm{C}}$ 's of $\sim 1.8 \times 10^{4} \mathrm{~cm}^{2}$ at $20 \mathrm{~T}$ and $4.2 \mathrm{~K}$ have been measured. Also, the liquid-infiltrated $\mathrm{Nb}(\mathrm{Ta})-\mathrm{Sn}$ composites have a damage strain tolerance nearly double that of commercial bronze-processed $\mathrm{Nb}-\mathrm{Sn}$ conductors.

[Contact: Ekin, (303) 497-5488]

Recently Published

Clark, A. F., and Goodrich, L. F., Characterization of a standard Reference Superconductor for Critical Current and a summary of other standard Research at NBS, Proceedings of the Tenth International Cryogenic Engineering Conference, Helsinki, Finland, July 31-August 3, 1984, pp. 433-437.

A standard reference material can be useful for the calibration of measurement apparatus and interlaboratory comparison of research results. We have carefully characterized the first practical superconductor SRM for critical current and it is now available from NBS as "Standard Reference Material 1457 Superconducting Critical Current - NbTi wire." The selection, characterization, and statistical analysis of this material will be described. The progress in other standards research will also be discussed for large conductor critical current, ac losses, stability, and critical field.

[ (303) 497-3253]

Ekin, J.W., and Hong, M., Electromechanical and Metallurgical Properties of Iiquid-Infiltration $\mathrm{Nb}-\mathrm{Ta} / \mathrm{Sn}$ Multifilamentary Superconductor, Applied Physics Letters, 45, No. 3, pp. 297-299 (1 August 1984).

Data are presented on the strain dependence of the critical current and critical field of $\mathrm{Nb}-\mathrm{Ta} / \mathrm{Sn}$ superconductors fabricated by the liquid sn infiltration process. The results show that liquid infiltrated $\mathrm{No}-\mathrm{Ta} / \mathrm{Sn}$ superconductors have several significant advantages over bronze-process $\mathrm{Nb} / \mathrm{Sn}$ super conductors: an overall $J_{C}$ that is $3-10$ times higher for magnetic fields in the range 13$20 \mathrm{~T}$, an irreversible (damage) strain limit twice as large, and a $J_{C}$ elastic-strain sensitivity less than half as large at fields above $\sim 16 \mathrm{~T}$. These improved properties are attributed to several unique characteristics of the liquid infiltration process: a tough $\mathrm{Nb}-\mathrm{Ta}$ matrix, fine equiaxial A15 grains, and a uniform stoichiometric Sn concentration.

[ (303) 497-5448]

Magnetic Materials and Measurements

Released for Publication

Goldfarb, R.B., Rao, K.V., and Chen, H.S., Differences Between Spin Glasses and Ferroglasses: $\mathrm{Pd}-\mathrm{Fe}-\mathrm{Si}$.

Near the multicritical point in the magnetic phase diagram, some alloys that appear to be simple spin glasses actually have an intermediate ferromagnetic like phase between the high-temperature paramagnetic and low-temperature spinglass states. The temperature dependences of the imaginary component of ac susceptibility and dc magnetization are presented to illustrate the subtle experimental differences between spin glasses and these ferroglasses.

[ (303) 497-3650]

\section{Recently Published}

Clark, A.F., and Cromar, M., Design of the NBS Magnetic Monopole Detectors, Proceedings of the Tenth Intrinational 
Magnetic Materials and Meas., cont'd.

Cryogenic Engineering

Helsinki, Finland, July

1984, pp. 365-368.

Several different configurations of magnetic monopole detectors have been built and operated at the National Bureau of Standards. These have been designed based on the following objectives: (1) study of the noise characteristics; (2) simplicity and ease of changing configurations; (3) operation in relatively large magnetic fields; and (4) optimum detector area. Satisfying these objectives has resulted in several compromises, but also a flexible and useful apparatus for studying the behavior of the SQUID detector loop combination with particular emphasis on noise sources that can simulate a monopole signal. Several sources of noise and techniques Ior their elimination will be discussed. Data trom the spectral analysis of the noise signals is be presented.

[ (303) 497-3253]

Cromar, M., Clark, A.F., and Fickett, F.R., Monopole Detection studies at NBS, Proceedings of the Conference on Monopole Detection by Induction Techniques, Ann Arbor, MI, October 5-9, 1983, pp. 477-480.

Magnetic monopole detectors have been under study and evaluation at NBS for the past year. This paper describes some of the work. It is the written version of a brief workshop contribution made at the MONOPOLE ' 83 conference held at the University of Michigan.

[(303) 497-5375]

Fickett, F.R., Magnetic Measurements, Calibrations, and standards: Report on a Survey, NBSIR 84-3018 (October 1984).

The report summarizes the analysis of responses to a survey of industrial needs for magnetic services and research.
[ (303) 497-3785]

\section{HLBCTROMAGNETIC INTERETRENCE}

Released for publication

Bensema, W.D., Reeve, G.R., and Koepke, G., A Multisensor Automated EM Field Measurement System, to be published in the Proceedings of the IMTC/85 Instrumentation/Measurement Technology conference, Tampa, EL, March 21-22, 1985 .

A system is being developed to monitor and collect electromagnetic (EM) field strength at 10 selected locations simultaneously. The system has two modes of operation: (1) for sampling EM fields that are stationary for times of the order of $200 \mathrm{~ms}$, and (2) for sampling changing EM fields with a system resolution of $10 \mu$ sec. Sensing elements consist of three orthogonal dipoles, each dipole feeding a separate data input channel for a total of 30 channels. Rf energy is converted to DC by a small diode detector at each dipole. Several sets of 30 sensing elements each are planned to cover specific measurement regions of amplitude and frequency. One of the initial sets will use $0.6 \mathrm{~cm}$ resistive dipoles: measurements of $r f$ fields with this set will normally be taken in the range $100 \mathrm{MHz}$ to $18 \mathrm{GHz}$, with an amplitude capability of up to several hundred volts per meter. Other sets will range in length up to $5 \mathrm{~cm}$ and may eventually include small loops. System computer data processing proceeds in real time and includes computation of total scalar amplitude at each of 10 probe locations, and statistical processing of resultant data.

[ (303) 497-3465]

Crawford, M.L , Performing EMI/EMC Evaluation of Electronic Equipment Using TMEM Cells, to be published in the proceedings of the RF Technology Expo, Anaheim, CA, January 25-27, 1985.

This paper summarizes the basic physical 
Electromagnetic Interference, cont'd.

and electrical properties which influence the design, operation and use of a transverse electromagnetic (TEM) cell. Guidelines are given for using a TEM cell for both radiated susceptibility and emissions measurements of electric components and equipment. The paper describes the test setups, outlines the test procedures, step by step, indicating precautions to observe to improve the repeatability and the limitations inherent in using TEM cells. Examples of some applications are then given. [ (303) 497-5497]

Cruz, J.E., and Larsen, E.B., Screenroom Measurements of Intenna Pactors. to be published in the proceedings of the IMTC/85 Instrumentation/Measurement Technology Conference, Tampa, FL, March $21-22,1985$.

The measurement of electromagnetic tields in a shielded enclosure (screenroom) has serious problems because of uncertain antenna factors and multipath reflections from conductive surfaces. Most electromagnetic interference antennas at NBS are calibrated in a known field at an open field site using the standard antenna method. Because these antenna factors are not necessarily applicable for making measurements in an enclosed screenroom, the measurement errors are difficult to determine. This paper presents the results of antenna factors determined in a screenroom using the two-antenna method. These antenna tactors are compared with antenna factors determined at an open field site and in an anechoic chamber. Experimental data are presented to show the variability of antenna factor as a function of frequency and location in the screenroom thereby providing an example of errorbounds.

\section{[ (303) 497-3763]}

FitzGerrell, R.G., site Attenuation, to be published in the proceedings of the North American Radio Science Meeting and the International IEEE/AP-S
Symposium, Vancouver, B.C., June 17-21, 1985.

Site attenuation is defined as the minimum relative insertion loss between two polarization-matched antennas located on a test site when one antenna is moved vertically over a specified height range. The following parameters must also be specified: separation distance between the two antennas, measured horizontally; antenna type and polarization; and impedance of the receiving and transmitting systems attached to the antenna terminals.

Site attenuation is a measure of performance of an open test site used to determine the levels of emissions, usually undesired, from sources of electromagnetic fields or to calibrate monopole and dipole antennas used for field strength measurements. An ideal site consists of an obstruction-free plane ground and the hemisphere above it both infinite in extent. Ground constants may range from typical earth values to values for good conductors. Site attenuation measurements are used to compare performance of real sites to some standard or reference site. Calculations presented here provide a reference for measurements to be made of a $30 \mathrm{~m}$ by $60 \mathrm{~m}$ wire mesh ground screen. [ (303) 497-3737]

Hi 11, D.A., and Koepke, G.H., An Array of Dipoles for Plane wave Synthesis. to be published in the proceedings of the 1985 International Symposium on Antennas and Propagation, Kyoto, Japan, August 20-25, 1985.

Phased arrays can be used to produce a nearly uniform plane wave in the near field. This paper describes $e 9 m i l$ array of dipoles which we have studled theoretically and experimentally. The element excitations are determined from a near-field synthesis technique that optimizes the field uniformity chroughout the test volume.

[ (303) 497-3472] 
Electromagnetic Interference, cont'd.

Kanda, M., and Nahman, N.S., Standards for Measurement of Electromagnetic Fields, to be published in the Proceedings of the IMTC/85 Instrumentation/Measurement Technology Conference, Tampa, FL, March 21-22, 1985.

The standards developed at NBS for measuremerts of electromagnetic fields are reviewed along with the industrial applications which engendered their development. Some attention is given to future measurement requirements and the NBS programs to meet them.

[ (303) 497-5320]

Larsen, E. B., and Cruz, J.E., E and $\mathrm{B}$ Fields in Transmission Lines and Coils for Susceptibility Testing, Probe Calibration, and RF Exposure Chambers, to be published in the Proceedings of the IMTC/85 Instrumentation/Measurement Technology Conference, Tampa, FL, March 21-22, 1985.

This paper deals with the instrumentation and design equations for several systems used to generate calculable electric (E) and magnetic (H) fields for electromagnetic compatibility (EMC) testing. These "standard" electromagnetic (EM) fields with known magnitude are used to: (a) test the susceptibility of electronic equipment to radiated fields, (b) calibrate $E$ and $H$ field probes for measuring and mapping fields, and (c) expose biological specimens in a known EM environment. The design and use of so-called transverse electromagnetic (TEM) cells terminated in their characteristic impedance are not described here because these devices are discussed adequately elsewhere.

[ (303) 497-3540]

Ma, M.T., and Koepke, G.H., Measurements of Unintentional Emissions.

A new method for determining the radiation characteristics of leakage from electronic equipment or other unintentional radiators for interference stud- ies is presented. The theoretical background and specific measurement procedures for the method using a transverse electromagnetic cell are outlined. The theory and measurements have been verified by the results of a simulated theoretical example and an experiment using a spherical. dipole radiator. Mathematical analysis of the uncertainties in the final, extracted results when the experimental data are degraded by the background noise and measurement imperfections is also available.

[ (303) 497-3800]

Muth, L.A., A Theory of Mutual Impedances and Mutiple Reflections in an N-Element Array Environment, to be published as NBS Technical Note 1078.

A general theoretical approach is formulated to describe the complex electromagnetic environment of an N-element array. The theory reveals the elementto-element interactions and multiple reflections within the array. From the formulation, it is found that the interaction between an excited element and an open-circuited element can be viewed as the sum of terms describing all possible signal paths within the array environment which start from the radiating element and terminate on the element under observation. Within all paths except the most direct one, multiple reflections between subgroups of elements take place. The resulting solution is highly structured and recursive and is discussed in detail in the text. Illustrative examples are provided to facilitate understanding of these ideas.

[ (303) 497-3603]

Randa, J., and Kanda, M., A PiniteElement Action Approach to the Characterization of Complex Electromagnetic Environments, to be published in the Proceedings of the 1985 International Symposium on Antennas and EM Theory, Beijing, China, August 25-27, 1985.

We outline an approach to the characterization of complicated electromagnetic 
Electromagnetic Interference, cont'd.

environments based on a finite-element approximation to the action functional of the electromägnetic field. A stationary point of the action is found by a numerical search, subject to constraints imposed by boundary conditions and by measurements of the field at some number of points. The technique is illustrated by a simple example.

[(303) 497-3150]

Randa, J., and Kanda, M., Directional Scanning of Complex Electromagnetic Environments, to be published in the Proceedings of the 1985 International Symposium on Antennas and Propagation, Kyoto, Japan, August 20-22, 1985.

As rf and microwave sources (both intentional and inadvertent) multiply, the electromagnetic (EM) environment in which electronic devices (and people) must function becomes increasingly complicated, while at the same time its characterization becomes more important. In order to completely characterize an EM environment without knowledge of the radiating sources, the sampling theorem requires that systematic measurements of the amplitude and phase of the field be made throughout the volume at spacings of no more than one-half wavelength (of the highest frequency present). This is often impossible and seldom convenient. There is a need for practical techniques which would determine useful properties of an EM environment from relatively few measurements. One recent suggestion for such a technique is to use directional measurements at a single point in conjunction with a plane-wave expansion of the field. This paper reports the formulation of the technique and the results of a simulation using it.

[(303) 497-3150]

Randa, J., and Kanda, M., A Directional Scanning Technique for Characterization of Complex Electromagnetic Environments, to be published in the Proceedings of the North American Radio Science Meeting and International
IEEE/AP-S Symposium, Vancouver, B.C., June $17-21,1985$.

The problem of characterizing complicated electromagnetic environments without actually measuring the field(s) throughout the entire volume of interest is of great practical importance in the areas of EMI/EMC electromagnetic hazard assessment, etc. The question is how to obtain useful information about the volume of interest from a reasonably small number of measurements.

A recent suggestion which appears to hold considerable promise is to use a directional probe to measure at one point the field incident from different directions and then to reconstruct or bound the field throughout the volume by using these measurements in conjunction with a plane-wave expansion of the field. We have now completed the formulation and performed simulations for the (vector) electric field, and we report the results in this paper. Simulation results are encouraging.

[(303) 497-3150]

Wilson, P.F., Adams, J.W., and Ma, M.T., Measurements of the Electromagnetic Shielding Capability of Materials, to be published in the forthcoming special issue of the Proceedings of the IEEE on Radio Measurement Me thods and standards (invited paper).

Shielding effectiveness is usually measured in terms of insertion loss, that is, the reduction in the fields coupled between a transmitter and receiver achieved by introducing the shield material or case, etc. Although the insertion loss concept is simply stated, problems arise when one attempts to interpret specific insertion loss measurements. Insertion loss values obtained in practice depend not only on the shield material introduced but also on antenna types used and their orientations, incident field distribution, and contact resistance. Variations in these factors can yield almost any level of insertion loss for the same shinld warple. These concepts will be discuspred 
Electromagnetic Interference, cont'd.

briefly to emphasize both the difficulty in making even relative insertion loss comparisons and the importance of controlling and understanding the measurement configurations.

[Contact: Ma (303) 497-3800]

Wilson, P.F., and Ma, M.T., Shielding Effectiveness Measurements in a Dual TEM Cell.

Small aperture theory is used to investigate the dual TEM cell. Analyzing coupling through an empty versus loaded aperture leads to a simple model of dual itu cell material shielding effectiveness measurements.

[ (303) 497-3842]

\section{Recently Published}

Juroshek, J.R., and Hoer, C.A., A High-Power Automatic Network Analyzer for Measuring the RF Power Absorbed by Biological samples in a TFM Cell, IEEE Transactions on Microwave Theory and Techniques, MTT-32, No. 8, pp. 818824 (August 1984).

A device for measuring the radiofrequency (RF) power absorbed by biological samples while they are being irradiated in a transverse electromagnetic (TEM) cell is described. The report discusses the design, calibration, and performance of this automated measurement system. The power absorption analyzer is based on a six-port type of automatic network analyzer, and operates at an incident power to the TEM cell of 1 to $1000 \mathrm{~W}$, over a frequency range of 100 to 1000 $\mathrm{MHz}$. Experiments show that an absorbed power of 0.02 to 0.05 percent of the incident power can be measured. Measurements of the power absorbed by a 1percent saline solution were made using the power absorption analyzer and by an independent calorimetric measurement. The two measurement techniques show excellent agreement.

[ (303) 497-5362]
Shafer, J.F., Field strength Levels in Vehicle Resulting From Communications Transmitters, National Institute of Justice Report No. 200-83 (June 1984).

This report provides the results of an exploratory study to measure the electric field strength levels inside an a tomobile from communications equipment (transmitters and associated antennas) typical of that likely to be operated in and around the automobile as a law-enforcement vehicle. Field strengths were measured with a calibrated probe at 10 locations within the test vehicle, with and without the driver's door open, and with and without front-seat occupants, at frequencies representing the frequency bands of 25 to 50,150 to 174,400 to 512, and 806 to $866 \mathrm{MHz}$. Levels of output power are given for the data presented. Field strength levels are also given for the situation when a metallic prisoner shield or a personal transceiver is used in a vehicle, together with a mobile transceiver, in some cases. Also included are field strength measurements of speed measuring radar devices used in vehicles.

[Contact: Jesch, (303) 497-3496]

Wilson, P.F., Chang, D.C., and Ma, M.T., Input Impedance of a Probe Antenna in a TEM Cell, IEEE Transactions of Electromagnetic Compatibility, EMC-26, No. 4, pp. 154-161 (November 1984).

The input impedance of a probe antenna exciting a transverse electromagnetic (TEM) cell is analyzed via a variational formulation. The resulting impedance is shown to consist of two distinct terms; an ordinary rectangular waveguide contribution and a gap perturbation. Numerically generated curves for both are given and suggest that a simple algebraic approximation for the input impedance should normally suffice. The resistive portion is found to be proportional to the square of the probe length, while the reactive portion is largely capacitive. These results should enhance the use of probes in- 
Electromagnetic Interference, cont'd.

serted in TEM cells either to excite or to measure tields.

[ (303) 497-3842]

Wilson, P.F., and Ma, M.T., Small Aperture Analysis of the Dual TrM Cell and an Investigation of Test object Scattering in a single TEM Cell, NBS Technical Note 1076 (October 1984).

Small aperture theory is used to investigate the dual TEM cell. Analyzing coupling through an empty versus a loaded aperture leads to a model of dual TEM cell shielding effectiveness measurements. Small obstacle scattering yields results for both the field perturbation and the change in a cell's transmission line characteristics due to the presence of a test object in a TEM cell. In each case, theoretical values are compared to experimental data.

[ (303) 497-3842]

\section{CEEE CAL BNIDAR}

June 10-14 (Boulder, CO)

Antenna Parameter Measurement by NearField Techniques. This course is designed for engineers and scientists concerned with the accurate measurement of microwave antenna parameters. Major emphasis will be placed on the theory of near-field antenna-antenna interactions; application to near-field scanning on planar, cylindrical, and spherical surfaces; and the computation of desired antenna characteristics from near-field data. Results comparing planar, cylindrical, and spherical methods will be presented, and the limitations and advantages of each method discussed. In addition, less detailed treatment will be offered of the extrapolation method for determining absolute gain and polarization. [Contact: Richard L. Lewis (303) 497-5196]
July 15-18 (Boulder, CO)

National Conference of standards Laboratories 1985 Workshop and Symposium: Managing Measurements to Achieve Quality. CEEE papers on waveform, microwave, and noise metrology. [Contact NCSL Secretariat MC1 04, Room 5001 Radio Building, NBS, Boulder, CO 80303]

July 22-24 (Monterey, CA)

1985 IEJE 22nd Annual Conference on Nuclear and Space Radiation Effects. This Conference will cover nuclear and space radiation effects and electromagnetic pulse effects on electronic devices, materials, circuits, and systems, as well as semiconductor processing technology and techniques for producing radiation-tolerant (hardened) integrated circuits. Specific topic areas are likely to include: basic radiationeffects mechanisms for materials and devices; radiation effects and spacecraft charging in satellites; radiation transport, energy deposition, dosimetry, and radiation facilities; methods of design and manufacturing for radiationhardened electronic devices, integrated circuits, and the effects of radiation on these devices; electromagnetic pulse phenomena, assessment of coupling, and measurement technology; single-event upset and latchup phenomena; hardness assurance technology and testing techniques; radiation effects on the materials and electronics of nuclear reactors (power and space); and new developments and new technologies of interest to the nuclear and space radiation effects comminity.

The Conference is sponsored by the Radiation Effects Committee of the IEEF: Nuclear and Plasma Sciences Society and cosponsored by the Defense Nuclear Agency, Sandia National Laboratories, and the Jet Propulsion Laboratory: the General Chairman for this conference is K. F. Galloway, Chief of CEEE's Semicon- 
1985 CEEE CALENDAR, cont'd.

ductor Devices and Circuits Division. [Contact: Sandra B. Kelley (301) 9213541]

July 23-25 (Vail, CO)

Short Course on Optical Fiber

Measurements. [Contact:

Robert L. Gallawa (303) 497-3761]

August 6-8 (Boulder, CO)

NBS EMI Metrology Short Course. The purpose of this course is to provide upto-date information on instrumental methods for measuring electromagnetic interference. Topics to be covered include: relevant NBS measurement services: open-site measurements as related to FCC requirements; the use of TEM cells, anechoic chambers, reverberating chambers, and probes; measurements of shielding effectiveness; and the electromagnetic environment, including conducted and outband EMI. Hands-on demonstration exercises in the NBS Boulder laboratories are part of this course, as is an FCC presentation on FCC practices and measurements. [Contact: Kent Zimmerman (303) 492-5151]

September 9-10 (Gaithersburg, MD)

VLSI Packaging workshop. The IEEE Components, Hybrids, and Manufacturing Technology Society and NBS are jointly sponsoring this Fourth Annual Workshop. At tendees are expected to be specialists in the field and participate in discussions. Papers are planned in the following areas: VLSI package design, package thermal design, VLSI package interconnection options, package electrical issues, integrating package design, GaAs IC packaging, VLSI package materials advancements, die-attach solutions for VLSI packages, and new failure mechanisrns in VLSI packaging. [Contact: Sandra B. Kelley (301) 921-3541]

November 5-6 (Gaithersburg, MD)

Workshop on Test Procedures for Precision Instrumentation and ATE Systems.
The purpose of this Workshop is to promote the exchange of information among researchers, users, manufacturers, testing companies, and calibration laboratories on procedures for testing and verifying the performance of precision instrumentation and ATE systems. Sessions are planned to cover first-article/acceptance testing, bid-sample testing, writing specifications and procedures, minimum-use specifications, test accuracy ratios, the cost of testing contrasted with its benefits, case histories of specific testing programs, optimum calibration strategies, and recommended practices. [Contact: John R. Sorrells (301) 921-2727]

December 5 (Gaithersburg, MD)

1985 Power Semiconductor Devices WorkShop. This Workshop is jointly sponsored by the IEEE Electron Devices Society and NBS and is held in conjunction with the IEEE Electron Devices Meeting in washington, D.C., which it follows. Topic areas include: packaging, power integrated circuits, three-terminal devices, and modeling. The format of the workshop calls for each topic area to be addressed by working groups of 15 to 30. Reports from the working groups will be developed and presented orally to all attendees in a concluding session. [Contact: Sandra B. Kelley (301) 921-3541]

\section{NEW STANDARD REFERIIIVCE MATERIALS}

The first practical superconducting standard reference material (SRM) has been released by the Electromagnetic Technology Division to the NBS Office of Standard Reference Materials for sale to the public. The certified parameter of SRM 1457, Superconducting Critical Current -- NbTi Wire, is critical current at magnetic fields of $2,4,6$, and 8 tesla at a temperature of $4.2 \mathrm{~K}$ and an electric field criterion of $0.2 \mu \mathrm{V} / \mathrm{cm}$. Information is given to permit the user to determine critical current for temperatures in the range 3.90 to $4.24 \mathrm{~K}$ 
NEW STANDARD REFERENCE MATERIAL, cont'd.

and electric field criteria from 0.05 to $0.2 \mu \mathrm{V} / \mathrm{cm}$.

SRM 1457 consists of a 2.2-m length of a multifilimentary, niobium-titanium, copper-stabilized wire, wound in a single layer on a spool having a core diameter of $8.7 \mathrm{~cm}$. The wire is evaluated for 34 parameters relating to current, voltage, magnetic field, temperature, strain, and physical specimen characteristics.

In conjunction with ASTM standard Test Method B714-82, D-C Critical Current of Composite superconductors, the new SRM is intended to provide means for calibrating apparatus used to measure key parameters of superconductor products and thus should be useful to buyers and sellers of superconductors, users of superconducting equipment, and researchers in superconducting technology.

\section{CERES SPONSORS}

National Bureau of Standards Department of Defense Defense Advanced Research Projects Agency; Combined Army/Navy/Air Force Calibration Coordination Group; Defense Nuclear Agency

U.S. Air Force

Bolling AFB; Hanscom AFB; Newark Air Force Station; Rome Air Development Center; Space Division; WrightPatterson AFB; U.S. Army Aberdeen Proving Ground; Aviation Research and Development Command; Fort Monmouth; Harry Diamond Laboratories; Fort Belvoir

U.S. Navy Aviation Logistics Center (Patuxent River); Naval Surface Weapons Center; Naval Weapons Support Center (Crane); office of Naval Research

Department of Energy Energy Systems Research; Fusion Energy

Department of Justice Law Enforcement Assistance Administration

Charles Stark Draper Laboratory

Electric Power Research Institute

Electronic Industries Association

International Copper Research Association

International Telecommunications Satellite Organization

Sandia National Laboratories

University of California Los Alamos Scientific Laboratory 
NBS-114A (REV. 2-8C)

U.S. DEPT. OF COMM.

BIBLIOGRAPHIC DATA

SHEET (See instructions)

1. PUBLICATION OR REPORT NO.

NBSIR $85-3181$

June 1985

4. TITLE AND SUBTITLE

Center for Electronics and Electrical Engineering Technical Progress Bulletin Covering Center Programs, October - December 1984 with 1985 CEEE Events Calendar

5. AUTHOR(S)

E. Jane Walters, compiler

6. PERFORMING ORGANIZATION (If joint or other than NBS, see instructions)

7. Contract/Grant No.

NATIONAL BUREAU OF STANDARDS

DEPARTMENT OF COMMERCE

WASHINGTON, D.C. 20234

8. Type of Report \& Period Covered October - December 1984

9. SPOHSORIHG ORCANHZATHON NAME ANO COMPLETE ADDRESS (Street, CIty, State, ZIR)

U.S. Department of Commerce

National Bureau of Standards

National Engineering Laboratory

Center for Electronics and Electrical Engineering

10. SUPPLEMENTARY NOTES

All technical information included in this document has been approved for

publication previously.

5 Document describes a computer program; SF-185, FIPS Software Summary, is attached.

11. ABSTRACT (A 200-word or less foctual summary of most significant information. If document includes a significant bibliogrophy or literoture survey. mention it here)

This is the ninth issue of a quarterly publication providing information on the technical work of the National Bureau of Standards Center for Electronics and Electrical Engineering. This issue of the CEEE Technical Progress Bulletin covers the fourth quarter of calendar year 1984. Abstracts are provided by technical area for both published papers and papers approved by NBS for publication.

12. KEY WOROS (Six to twelve entries: alphabetical order: capitolize only proper names; and separate key words by semicolons) antennas; electrical engineering; electrical power; electromagnetic interference; eloctronics; instrumentation; laser; magnetics; microwave; optical fibers; semiconductors; superconductors

13. AVAILABILITY

U. Unlimited

For Official Distribution. Do Not Release to NTIS

Order From Superintendent of Documents, U.S. Government Printıng Office, Washington, D.C. 20402.

14. NO. OF

PRINTED PAGES

31

15. Price

[X] Order From National Technical Information Service (NTIS), Springfield, VA. 22161

$\$ 8.50$ 



\section{CENTER FOR ELECTRONICS AND ELECTRICAL FNGINEERING}

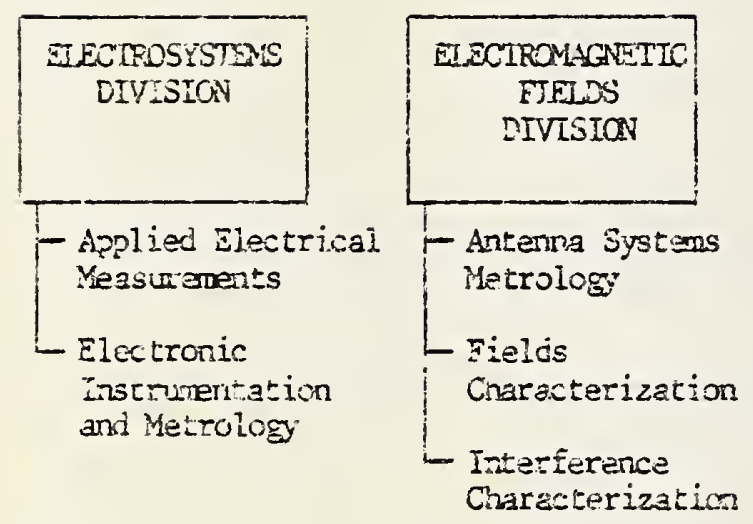

Center Headguatters (720)

Electrosysters Division (72)

Electronametic Fields Division (723)

Electrazgatic Tectulology Division (724)

Sariconduc or 2ateriais ard Processes Iivision (125)

Senicorituc or Devices and Circuits Divising (725)
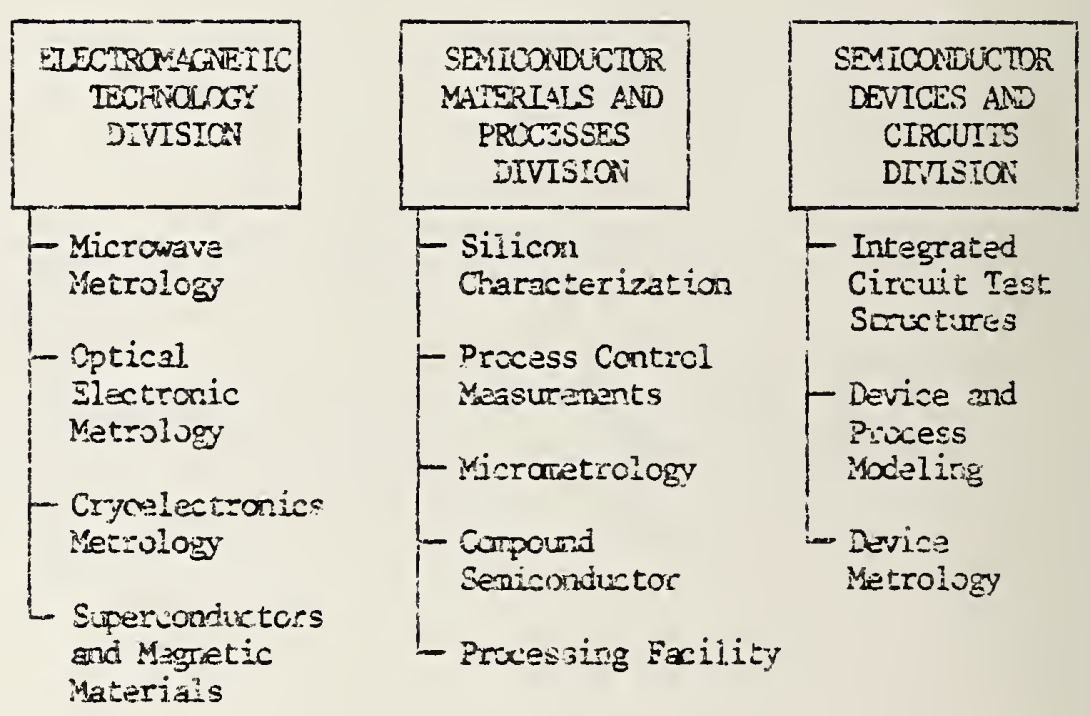

WRY CORIACTS

\section{IMPCEMTION:}

for edtitimal infortation on the Center for Elentronies asd Fientricai Engineering, write or cali:

Center for Electronics anh Elestrical Enginesring

Viationat Buranu of Scandards

Metroliby Euiluing, Rasi E-358

Ceithersourg, Yarjiand :Co39

Director, Mr. Judson C. French (301) 921-3357 tenuty Director, M. Kóbert I. Scace (301) 921-3357 Chief, DE. Cskars Petersons (301) 921-23:3 hief, Mr. Charles K.S. Miller (303) 407-3131 Chief, Dr. Robert A. Kanper (303) 497-35j5 Acting Thief, itr. Frark $\bar{F}$. Oeitinger (30i) 92i-37ón Chier, Dr. Mennath E. Cälloway (301) 921-3541 